\title{
Analisis Miskonsepsi Pada Buku Ajar Biologi SMA Kelas XII
}

\author{
Renny Agustina ${ }^{1}$ Herbert Sipahutar $^{2}$ Fauziyah Harahap $^{3}$ \\ ${ }^{1}$ Guru Biologi di SMA Negeri 1 Binjai Jln. WR. Mongonsidi No. 10 Binjai Kota \\ ${ }^{2}$ Program Studi Pendidikan Biologi Pascasarjana Universitas Negeri Medan, Sumatera Utara, Indonesia \\ E-mail: rennyagustina@gmail.com
}

\begin{abstract}
This research was emerged based on the facts about the presence of many conceptual problems that lead misconceptions in biology textbooks while teachers rely too much on textbooks as learning source in class. This study were aimed to analyze the misconceptions in the high school biology textbook for grade 12 which shall be used by high school students, grade 12 in the city of Binjai, especially for the subjects (growth and development, metabolism, heredity, evolution, and biotechnology) as well as to determine the percentage of misconceptions categories (misidentifications, overgeneralizations, oversimplification, obsolete concept and term, under generalizations). The research method used in this research is descriptive. The concepts contained in the textbook were analyzed by using analysis of documents or textbooks based on the criteria of each misconception categories contained in the instrument for misconceptions identification and then comparedto foreign textbooks. The results of this study showed that: (1) the percentage of misconceptions on the subject of (a) the growth and development $(26,09 \%)$; (b) metabolism $(26,09 \%)$; (c) heredity $(26,09 \%)$; (d) evolution $(8,69 \%)$; and (e) biotechnology $(13,04 \%)$; (2) the percentage of misconceptions categories: (a) misidentifications (8,69\%); (b) overgeneralizations $(17,40 \%)$; (c) oversimplifications $(69,56 \%)$; (d) obsolete concept and term $(0,00 \%)$; (e) under generalizations $(4,35 \%)$.
\end{abstract}

Keywords: Misconception, misidentifications, overgeneralizations, oversimplification, obsolete concept

\section{PENDAHULUAN}

Buku ajar di sekolah dibuat untuk pegangan belajar siswa. Namun biasanya guru juga menggunakan buku ajar yang sama dengan yang dipakai oleh siswa. Seharusnya guru memiliki buku pegangan yang lain yang berasal dari sumber yang terpercaya misalnya buku teks. Buku ajar biasanya disusun oleh tim guru atau dosen dengan menggunakan buku sumber yang berbeda-beda, sehingga kualitasnya juga berbeda-beda. Kualitas buku ajar dapat dinilai berdasarkan validitas buku ajar dengan kriteria tertentu, konten/isi spesifik biologi, keterbacaan atau kemampuan menyesuaikan dan miskonsepsi (Abimola \& Baba, 1996).

Dalam pembelajaran biologi banyak sekali konsep-konsep yang harus dikuasai oleh siswa dan terdapat keterkaitan antara satu konsep dengan konsep yang lain. Hal ini menyebabkan kesulitan bagi siswa untuk memahami konsep tersebut. Pemahaman konsep yang berbeda dengan konsep ilmiah disebut miskonsepsi (Kose, 2008).
Miskonsepsi pada biologi dapat bersumber dari buku ajar yang memuat uraian materi yang salah, dan dapat memicu miskonsepsi, guru-guru yang mengalami miskonsepsi, kesalahan bahasa, yang muncul akibat budaya masyarakat yang terlanjur salah kaprah dalam mendefinisikan sesuatu secara ilmiah, intuisi yang salah.Hal ini merupakan faktor yang paling dominan mengakibatkan miskonsepsi, metode mengajar yang tidak tepat juga dapat menyebabkan terjadinya miskonsepsi (Bukit, 2011). Ergul et al., (2011) juga menyatakan bahwa miskonsepsi yang seringkali ditemui dalam pembelajaran biologi di sekolah adalah kesulitan dalam memahami konsep-konsep bilogi yang bersifat abstrak dan sulit untuk dipahami baik dari pihak siswa, guru maupun dalam buku ajar yang digunakan. Selain itu penggunaan istilah-istilah yang kurang dikenal bahkan tidak dikenal sama sekali dalam menjelaskan atau mendefinisikan konsep baru bisa memicu terjadinya miskonsepsi, sehingga siswa 
tidak mampu mengembangkan pemahamannya (Cahyaningsih, 2006).

Penelitian Dikmenli, Cardak, dan Oztas (2009) telah menemukan dan mengelompokkan miskonsepsi pada materimateri biologi dalam buku sains dan teknologi tingkat pendidikan dasar, yaitu : misidentification (kesalahan identifikasi), overgeneralization (generalisasi yang berlebihan), oversimplification (penyederhanaan yang berlebihan), obsolete concept and term konsep (istilah pada konsep buku tersebut sudah lama atau konsep atau istilah yang tidak digunakan lagi dengan perkembangan ilmu biologi saat ini), under generalization (konsep yang terlalu di khususkan). Khairati (2011) menemukan miskonsepsi pada 9 buku biologi SMA kelas XI pada materi jaringan tumbuhan di Kabupaten Langkat yang meliputi misidentifications $42,19 \%$, overgeneralization $23,44 \%$, oversimplifications $6,25 \%$, obsolete concept and termsi $14,06 \%$ dan under generalizations $14,06 \%$. Nasution (2012) menemukan miskonsepsi pada 6 buku biologi SMA kelas XI pada materi sistem respirasi dan sistem eksresi di SMA se-Mandailinggodang, yaitu : misidentifications $16,67 \%$ overgeneralization $36,67 \%$, oversimplifications $20 \%$, obsolete concept and terms $0 \%$ dan under generalizations $26,67 \%$.

Masih banyak di temukannya masalah konseptual yang menyebabkan miskonsepsi dalam buku ajar biologi menjadi suatu alasan bahwa menemukan dan menganalisis masalah-masalah konseptual pada buku ajar biologi khususnya kelas XII akan memberikan manfaat bagi pihak-pihak yang terlibat dalam penggunaan serta penyusunan buku ajar yakni terutama siswa, guru dan penulis buku. Hasil penelitian ini dapat menjadi salah satu acuan untuk menyusun buku ajar yang baik dengan menghilangkan masalah-masalah konseptual yang diteliti untuk terciptanya peningkatan mutu pendidikan. Oleh karena itu, penelitian tentang analisis masalahmasalah konseptual pada buku ajar Biologi SMA ini penting dilakukan.

\section{METODE PENELITIAN}

Penelitian di lakukan di SMA Negeri se-kota Binjai, yang terdiri dari 7 sekolah SMA Negeri.Pelaksanaan penelitian dilakukan pada Januari sampai dengan Maret 2016. Objek pada penelitian ini merupakan konsep-konsep pada buku ajar biologi kelas XII yang diterbitkan oleh Pusat Perbukuan Departemen Pendidikan Nasional tahun 2009 yang dibagikan dan wajib dimiliki oleh siswa untuk belajar maupun oleh guru untuk mengajar. Jenis penelitian yang dilakukan adalah penelitian deskriptif kuantitatif.Berupa identifikasi, klassifikasi dan analisis miskonsepsi secara deskriptif pada konsep-konsep yang terdapat pada buku ajar biologi SMA kelas XII. Pada analisis juga dijabarkan frekwensi miskonsepsi pada setiap pokok bahasan buku ajar kelas XII dan disajikan dalam bentuk diagram.

\section{Langkah-Langkah Pengumpulan Data 1. Tahap Persiapan}

Pada tahapan ini dilakukan observasi buku-buku pelajaran Biologi yang digunakan oleh guru dan siswa pada setiap sekolah SMA Negeri di Kota Binjai sehingga diperoleh data buku ajar pelajaran biologi yang akan dianalisis pada penelitian ini.

\section{Tahap Pelaksanaan}

Pada tahap ini buku biologi yang akan dianalisis terlebih dahulu konsep-konsep yang terdapat pada buku ajar yang sama digunakan oleh siswa maupun guru yang tertuang dalam peta konsep pada setiap pokok bahasan dalam buku ajar tersebut. Adapun konsep-konsep pokok bahasan yang dipelajari pada siswa kelas XII ini secara garis besar antara lain mengenai : pertumbuhan dan perkembangan pada tumbuhan, metabolisme, hereditas, evolusi, dan bioteknologi. Data penjebaran konsep buku ajar yang diperoleh kemudian dianalisis berdasarkan konsep yang benarpada hasil studi pustaka yang disesuaikan dengan konsep pada buku ajar Biologi karangan Campbell, et.al (2006), Kimball (terjemahan 1996), dan jurnal internasional yang berkaitan dengan konsep 
pada tiap pokok bahasan. Hasil konsep yang benar pada hasil studi pustaka digunakan untuk menentukan apakah konsep pada pokok bahasan sel dalam buku ajar yang telah di teliti tergolong miskonsepsi atau tidak.

Pada buku ajar, terdapat konsep-konsep yang dianalisis dengan menggunakan teknik analisis dokumen/buku ajar, yaitu : setiap konsep dibaca secara maksimal sebanyak dua kali. Disetiap kalimat yang ditemukan miskonsepsi diberi tanda khusus.Konsep-konsep pada buku ajar dianalisis berdasarkan kriteria pada setiap kategori miskonsepsi yang tercantum dalam instrumen identifikasi miskonsepsi. Dan disesuaikan dengan konsep pada literatur yakni : yang disesuaikan dengan konsep pada buku ajar Biologi karangan Campbell,et.al (2006), Kimball (terjemahan 1996), dan jurnal internasional yang berkaitan dengan konsep. Langkah berikutnya adalah melakukan pencatatan cuplikan setiap kalimat yang telah dikelompokkan pada setiap kategori miskonsepsi ke dalam lembar kerja analisis miskonsepsi, yaitu :misidentifications, overgeneralizations, oversimplifications, obsolete concepts and terms, atau under generalizations.

Proses pencatatan setiap kalimat dalam konsep buku biologi kelas XII ini disertai dengan konsep yang benar yang disesuaikan dengan konsep ilmiah sebenarnya pada literature ilmiah yang digunakan yakni : buku ajar Biologi karangan Campbell,et.al (2008), Kimball (terjemahan 1996), dan jurnal internasional yang berkaitan dengan konsep ilmiah yang benar. Keseluruhan hasil pencatatan ini kemudian dikumpulkan dalam lembar rekapitulasi hasil analisis miskonsepsi.Pada akhir analisis ini dilakukan perhitungan persentase hasil rekapitulasi analisis miskonsepsi pada setiap pokok bahasan. Perhitungan ini dilakukan pada setiap kategori miskonsepsi pada setiap pokok bahasan buku biologi. Dari hasil ini ditarik kesimpulan hasil analisis miskonsepsi pada setiap pokok bahasan biologi kelas XII.

Pengacuan pada buku ajar merupakan buku pelajaran dalam bidang studi biologi yang merupakan buku standar yang telah diberikan dan wajib dipakai oleh para siswa dalam belajar maupun oleh guru ketika mengajar di dalam kelas, dimana buku ajar ini disusun oleh para pakar dalam bidang tersebut untuk maksud-maksud dan tujuan instruksional, yang lengkapi dengan saransarana pengajaran yang serasi dan mudah dipahami oleh para pemakainya di sekolah sehingga dapat menunjang suatu program pengajaran di dalam kelas. Sehingga penggunaan buku ajar tersebut didasarkan pada tujuan pembelajaran yang mengacu pada kurikulum, yakni : kurikulum 2006. Dimana acuan kurikulum ini sangat penting mengingat kurikulum berisikan tentang perangkat rencana dan pengaturan mengenai tujuan, isi, dan bahan pengajaran serta cara yang di gunakan sebagai pedoman penyelenggaraan kegiatan pembelajaran untuk mencapai tujuan pendidikan.

\section{HASIL DAN PEMBAHASAN}

Hasil analisis miskonsepsi pada buku ajar biologi kelas XII di SMA Negeri SeKota Binjai diperoleh 23 miskonsepsi, pada aspek : (1) misidentification (kesalahan dalam mengidentifikasi suatu konsep) berjumlah $=2$, yakni miskonsepsi mengenai: pokok bahasan metabolisme 2; (2) overgeneralizations(terlalu mengumumkan atau mengeneralisasi suatu konsep) berjumlah $=4$, yakni miskonsepsi pada pokok bahasan pertumbuhan perkembangan $=1$, metabolisme $=1$, hereditas $=1$, dan evolusi $=1$; (3) oversimplifications

(terlalu menyederhanakan suatu konsep, atau konsep dikhususkan pada suatu proses atau mekanisme yang terlalu disederhanakan berjumlah $=16$, yaitu miskonsepsi pada pokok bahasan pertumbuhan dan perkembangan $=4$, metabolisme $=3$, hereditas $=5$, evolusi $=1$, dan bioteknologi $=$ 3; (4) obsolete concept and terms (konsep dan istilah pada konsep buku tersebut sudah lama atau tidak digunakan lagi dengan perkembangan ilmu biologi saat ini) tidak terdpat miskonsepsi; dan (5) under generalizations (konsep yang terlalu dikhususkan) berjumlah $=1$, yaitu 
miskonsepsi pada pokok bahasan pertumbuhan perkembangan. Miskonsepsi pada buku ajar biologi kelas XII di SMA Negeri Se- Kota Binjai dapat disajikan pada
Tabel 1. Miskonsepsi berdasarkan pokok bahasan dapat disajikan pada Table 2 .

Table 1. Miskonsepsi pada Buku Ajar Biologi Kelas XII di SMA Negeri Se-Kota Binjai

\begin{tabular}{|c|c|c|c|c|c|c|c|c|}
\hline \multirow{2}{*}{ No. } & \multirow{2}{*}{ Pokok Bahasan } & \multicolumn{5}{|c|}{ Aspek Penilaian } & \multirow{2}{*}{ Jumlah } & \multirow[t]{2}{*}{$\%$} \\
\hline & & 1 & 2 & 3 & 4 & 5 & & \\
\hline 1. & $\begin{array}{l}\text { Pertumbuhan dan Perkembangan } \\
\text { Tumbuhan }\end{array}$ & 0 & 1 & 4 & $\begin{array}{c}\text { Tidak } \\
\text { ada }\end{array}$ & 1 & 6 & 26.09 \\
\hline 2. & Metabolisme & 2 & 1 & 3 & $\begin{array}{c}\text { Tidak } \\
\text { ada }\end{array}$ & $\begin{array}{l}\text { Tidak } \\
\text { ada }\end{array}$ & 6 & 26.09 \\
\hline 3. & Hereditas & $\begin{array}{c}\text { Tidak } \\
\text { ada }\end{array}$ & 1 & 5 & $\begin{array}{c}\text { Tidak } \\
\text { ada }\end{array}$ & $\begin{array}{l}\text { Tidak } \\
\text { ada }\end{array}$ & 6 & 26.09 \\
\hline 4. & Evolusi & $\begin{array}{c}\text { Tidak } \\
\text { ada }\end{array}$ & 1 & 1 & $\begin{array}{c}\text { Tidak } \\
\text { ada }\end{array}$ & $\begin{array}{l}\text { Tidak } \\
\text { ada }\end{array}$ & 2 & 8.69 \\
\hline 5 & Bioteknologi & $\begin{array}{c}\text { Tidak } \\
\text { ada }\end{array}$ & $\begin{array}{c}\text { Tidak } \\
\text { ada }\end{array}$ & 3 & $\begin{array}{c}\text { Tidak } \\
\text { ada }\end{array}$ & $\begin{array}{l}\text { Tidak } \\
\text { ada }\end{array}$ & 3 & 13.04 \\
\hline & Jumlah & 2 & 4 & 16 & $\begin{array}{c}\text { Tidak } \\
\text { ada }\end{array}$ & 1 & 23 & 100 \\
\hline
\end{tabular}

Table 2.Miskonsepsi Berdasarkan Pokok Bahasan Pada Buku Ajar Biologi.

\begin{tabular}{|c|c|c|c|}
\hline No. & $\begin{array}{c}\text { Aspek Penilaian } \\
\text { Miskonsepsi }\end{array}$ & Pokok Bahasan & Jumlah \\
\hline 1 & Misidentifications & a. Metabolisme & 2 \\
\hline 2. & Overgeneralizations & $\begin{array}{ll}\text { P. } & \text { Pertumbuhan dan Perkembangan } \\
\text { p. } & \text { Metabolisme } \\
\text { f. } & \text { Hereditas } \\
\text { i. } & \text { Evolusi }\end{array}$ & 4 \\
\hline 3 & Oversimplifications & $\begin{array}{ll}\text { a. } & \text { Pertumbuhan dan perkembangan } \\
\text { b. } & \text { Metabolisme } \\
\text { f. } & \text { Hereditas } \\
\text { d. Evolusi } \\
\text { k. } & \text { Bioteknologi }\end{array}$ & 16 \\
\hline 4. & $\begin{array}{l}\text { Obselete Concepts and } \\
\text { Terms }\end{array}$ & Tidak terdapat miskonsepsi & 0 \\
\hline 5. & Under Generalizations & P. Pertumbuhan dan Perkembangan & 1 \\
\hline & Jumlah & & 23 \\
\hline
\end{tabular}

Hasil analisis miskonsepsi pada Buku Ajar Biologi Kelas XII di SMA Negeri SeKota Binjai, diperoleh 23 miskonsepsi, pada aspek: (1) misidentification(kesalahan dalam mengidentifikasi suatu konsep) berjumlah $=2 \quad(8.69 \%)$; overgeneralizations (terlalu mengumumkan atau menggeneralisasi suatu konsep) berjumlah $=4(17.40 \%)$; (3) Oversimplificatons

(terlalu menyederhanakan suatu konsep, atau konsep dikhususkan pada suatu proses atau mekanisme yang terlalu disederhanakan berjumlah $=16$ (69.56\%); (4) obsolete concepts and terms (konsep dan istilah pada konsep buku tersebut sudah lama, kategori ini untuk konsep atau istilah yang sudah tidak digunakan lagi dengan perkembangan ilmu biologi saat ini) tidak terdapat miskonsepsi (0,00\%); dan (5) under generalizations (konsep yang terlalu dikhususkan) berjumlah $=1(4.35 \%)$.

Miskonsepsi pada Buku Ajar Biologi Kelas XII di SMA Negeri Se-Kota Binjai diperoleh dari: (1) pokok bahasan pertumbuhan dan perkembangan $=6$ (26.09\%); (2) pokok bahasan metabolisme $=6(26.09 \%)$; (3) pokok bahasan hereditas $=6(26.09 \%)$; (4) pokok bahasan evolusi $=2(8.69 \%)$; (5) pokok bahasan 
bioteknologi= $3(13.04 \%)$. Berdasarkan

Kelas XII di SMA Negeri Se-Kota Binjai pokok bahasan pada buku ajar Biologi

dapat disajikan pada Gambar berikut.

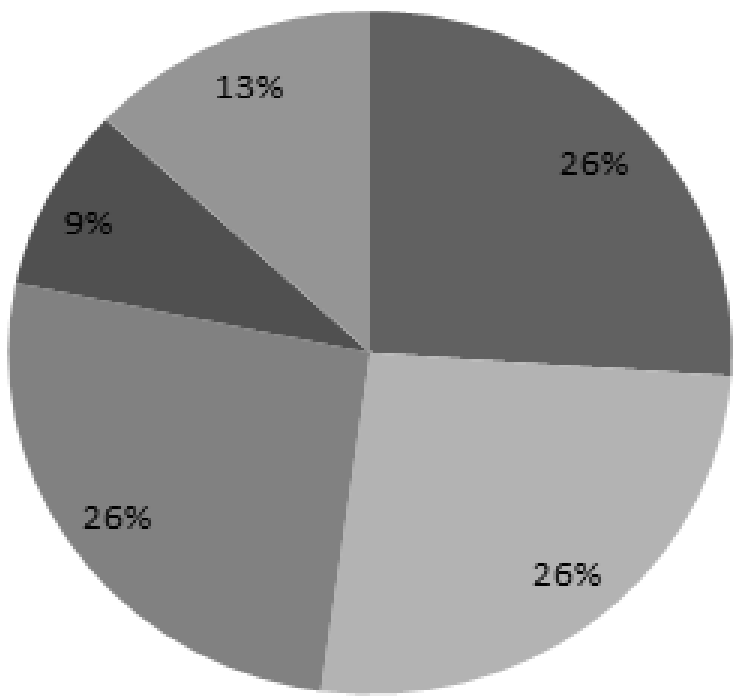

Pertumbuhan dan
perkembangan
Metabolisme
Hereditas
Evolusi
Bioteknologi

Gambar 1.Sebaran Miskonsepsi pada Buku Ajar Biologi Kelas XII di SMA Negeri Se-Kota Binjai

\section{SIMPULAN}

Beradasarkan hasil penelitian analaisis miskonsepsi pada Buku Ajar Biologi SMA Negeri Kelas XII di Kota Binjai dapat ditarik kesimpulan:

1. Variasi miskonsepsi pada masingmasing pokok bahasan yaitu: (a) pertumbuhan dan perkembangan meliputi: over-generalizations dan oversimplifications; (b) metabolisme meliputi: misidentificationsovergeneralizations dan oversimpli-fications; (c) hereditas meliputi: over-generalizations dan oversimplifications; (d) evolusi meliputi: overgeneralizations dan oversimplifications; (e) bioteknologi hanya oversimplifications.

2. Persentase kategori miskonsepsi: (a) misidentifications $\quad(8.69 \%)$; overgeneralizations $\quad(17.40 \%)$; oversimplifications $\quad(69.56 \%)$; obsolete concepts and termsi $(0.00 \%)$; (e) under generalizations $(4.35 \%)$.

\section{DAFTAR PUSTAKA}

Abimola, I.O., \& Baba, S. (1996). Misconceptions and alternative cenceptions in science textbooks: The role of teacher as filters. The American Biology Teacher.58 : 14-19.

Bukit, I. (2011). Identifikasi Miskonsepsi Guru Biologi pada Materi Respirasi dan
Fotosintesis di SMA se-Kota Medan.Tesis tidak diterbitkan.Medan : Program Pascasarjana Universitas Negeri Medan.

Cahyaningsih, E. (2006). Identifikasi Miskonsepsi pada Konsep Fotosintesis dengan Menggunakan Teknik CRI (Certainly Indeks Respon). Skripsi S1 pada FPMIPA UPI Bandung (http: www.bioupi.com, diakses 3 Agustus 2015.

Campbell, Reece, Mitchell, (2006). Biology, $6^{\text {nd }}$ ed. California : Benjamin Cummings Publishing Company.

Campbell, Reece. (2008). Biologi Edisi Kedelapan Jilid1. Terjemahan oleh: Damaring Tyas Wulandari. Jakarta: Erlangga.

Dikmenli, M., \& Cardak, O. (2009). Conceptual Problem In Biology-Related Topics In Primary Scince and Tecnolgy Texbooks In Turkey. International Journal of Enviromental \& Science Education, 4 : 429-440.

Ergul, R, Yeter Simsekli, Sevgil Caliz. Zehra Ozdilek, Sirin Gocmencelebi, \& Meral Sanli.(2011). The Effects of Inquiry-Based Science Teaching On Elementary School Students' Science Process Skills And Science Attitudes. Bulgarian Journal of Science and Eduction Policy (BJSEP), 5: 48-68.

Khairati, S. (2011).Analisis Miskonsepsi Pokok Bahasan Jaringan Tumbuhan pada Buku Biologi SMA Kelas XI di Kabupaten Langkat.Tesis tidak diterbitkan. Medan: 
Program Pasca Sarjana Universitas Negeri Medan.

Nasution, Lely, O. (2012). Analisis Miskonsepsi Siswa, guru, dan Buku Biologi Kelas XI Pada Materi sistem Respirasi dan Sistem Eksresi di SMA SeMandailinggodang Kabupaten Mandailing Natal. Program Pasca Sarjana universitas negeri Medan.

Novak,J.D. \& Canas.A. (2004). Building On New Constructivist Ideas and Map ToolS to Create a New Model for Education Proceeding of The First Int. Conference on Concept Mapping, Pamplona, Spain. $1^{\text {st }}$ June.

Odom, A. L. (1993). “Action Potentials \& Biology Te xtbooks: Accurate, Misconceptions or Avoidance?" The American Biology Teacher.55 (8): 468-472.

O-Saki, K. M., \& 4eSamiroden, W. D. (1990).Children's Conception of Living and Dead.Journal of Biological Education, 24: 199-207.

Panggabean, Henny N. S. (2011) Analisis Miskonsepsi Siswa dan Guru Biologi Tentang Materi Klassifikasi Dunia Hewan Pada SMA Se-Kecamatan medan Helvetia. Program Pascasarjana Universitas Negeri Medan. 